\title{
V. On the different kinds of cadmia, and particularly those of zinc and cobalt
}

\section{I.I. Bindheim}

To cite this article: I.I. Bindheim (1799) V. On the different kinds of cadmia, and particularly those of zinc and cobalt , Philosophical Magazine Series 1, 4:15, 250-255, DOI: 10.1080/14786449908677067

To link to this article: http://dx.doi.org/10.1080/14786449908677067

Published online: 18 May 2009.

Submit your article to this journal $₫$

Џ Article views: 3

Q View related articles $\sqsubset$ 


\section{On the different Kinds of Cadmia, and}

$3^{\mathrm{d}}$, A $1 \mathrm{ky}$-rocket, of a large diameter, would be of equrat fervice. It would alfo carry, from the veffel to the fhore, a ftring capable of drawing a rope after it. C. Ruggieri, whom I have confulted on this fubject, told me, that he mate fome four inches in diameter, which rofe to a great height; and that, with a fring attached to them, they would go to the diftance of four or five hundred fathoms, which is more than would be neceffary. They may be kept in a ftate fit for fervice two years, if depofited in a dry place.

Laftly, A fourth plan for faving the crew of a fhipwrecked veffel, is that of throwing from the veffel into the fea an empty cark with a cord attached to it. The wind and the waves would drive the cafk to the fhore, and afford the means of eftablifhing that rope of communication already mentioned. Each of thefe methods may be improved, but I cannot at prefent enter into any detail *.

V. On the different Kinds of Cadmia, and particularly thofe of Zinc and Cobalt. By I. I. Bindherm of Mofcowt.

II

HE fureft method of claffing minerals is without doubt to arrange them, not according to their external characters, but according to their internal component parts. For, though the former in fome meafure ferve for difcrimination, and are therefore not altogether ufelefs, they are not fo precife and certain as to form a bafis for a fyftem of mineralogy,

* The author of the above papers fays, that he announced his difcovery in the Africbes de Paris on the 2gth of Jamary 1794 . However this may be, we know that one of his methods, that of conveying a rope to the fhore, by attaching it to a bullet or bomb to be afterwards. fired from a cannon or mortar, was propofed a few years ago by a ferjeant or officer of artillery at Woolwich, named Bell. Some experinents of the fame kind made at Portfmouth, we believe, anfivered expectation. The ufe of a kite or rocket feems to deferve attention; and we do not hefitate to fay, that the former could hardly fail of producing the defired effect. At any rate it might be cafily tried. EDrToR.

+ From Newo Nordifcko Beytraze, by Profeffor Pallas, Vol. VI. 
fince the attentive naturalift is fufficiently taught, by experience, that in the mincral hinguom fubtances of the fame genus, though different in external form, confift often of the fame component parts; and thit chen hodies of the like kind differ in their component parts, though perfectly alike in their external appearance. As this is the cafe, we can find no better guide to conduct us to an invariable claffification, arrangement, and definition of mineral bodies than chemiftry; a knowledge which muft be united with that of the external characters of minerals.

To give an inftance of the uncertainty which arifes when thefe are feparated, I fhall here mention thofe ores which are known by the name of cadmia ; for it would feem, by the many improper denominations which are often founded on their external characters; as if we were almoft conducted back to the dark age of Cadmus, from whom the Europeans are faid to have firtt learnt the art of fufing ores on a large fcale, and from whom, in all probability, the term cadmia had its origin. In this refpect chemical knowledge is a better guide than external characters, and the names thence deduced, and often very improperly; it enables us to define minerals with more accuracy, and conducts us nearer than the latter to the real knowledge of nature in this department without which all mineralogical knowledgre muft be uncertain and imperfect. As it would be fuperfluous to fay more on this fubjest, I thall, for the prefent, confine myfelf to the cadmias, and thofe ores alone which, when decompofed in a proper manner, and fully purified, yield thofe metals called zinc and cobalt,

\section{of ZrNc.}

Ores that contain zinc are found in numerous varieties and of different forms. Sometimes they are combined with oxygen and the fuilphuric acid; and fometimes there are found in them, befides zinc, various foreign component parts, fuch as argil and filiceous earth, a little iron, lead, 
and, at times, alfo a fmall portion of copper. In blende the fulphur is combined with iron, and the particles of zinc are feattered through the mixture. The fo called furnace calamine is obtained by the fufion of fome kinds of lead ore when the particles of zinc are fublimated by ftrong heat to a cooler place of the furnace called the zinc floot, where they adhere in the form of a grey or yellowifh ftone. In preparing brafs, and other operations of the like kind, the fublimated zinc calx is collected under the name of wubite nicbt; but what adheres lower down, and becomes a hard mafs, is called grey tutia; and this fubftance, as fome fulphureous vapour feems to adhere to it the longer it lies expofed near the fmelting houfes, becomes, by the effects of the atmofphere, always more proper. for ufe. Befides the above, we have zinc calx, zinc fpar, tutanego ore, the laft of which was firt difcovered in China; but I am convinced, by experiments, that a like ore, which is natural flowers of zine, is found in Germany in the Thomas-ftollen at Bleiberg. We have alfo zeolite-formed calamine, zinc blende, glittering blende, black blende, reddifh brown, phofphorifed, greenifh-yellow, white, and yellow blende. Such kinds are found in England, Siberia, China, Sweden, Silefia, Saxany, Scc.

In examining thefe fubftances various chemifts have rendered great fervice to mineralogy, particularly Brand and Schwab, counfellors of the mines in Sweden; and thefe were followed by Juft, Pott, Henkel, and, above all, Margraaf, who employed great care and accuracy in fufing and examining them; but Bergmann, to whom fcience is fo much indebted, has given moft excellent models for the decompofition of thefe ores. Whether there be native zinc or not, has never yet been fully afcertained; and we muft ftill remain in doubt until the accourt of its being found in the ifland of Naxos, in the Archipelago, be better confirmed. The zino ore of Gollar, that found in Cornwall, and a little of the Swedin, can be rendered ufeful and prom 
ductive. The zinc obtained from China, under the name of tutanego, is confidered to be purer than the German, and therefore a fmall difference is obferved in their fpecific gravities.

The properties of zinc feparated from its ore, and purified, are, that it fcarcely undergoes any variation in atmopheric air or in water; and that, by the addition of copper, in different proportions, you obtain brafs, pinchbeck, prince's metal, Manheim gold, \&cc. All acids deprive it of its inflammable matter, and diffolve it with effervefcence. With the vitriolic acid it gives a cryftalline falt, which is fulphat of zinc, or, as it is commonly called, white vitriol. That white vitriol which is obtained not in a cryftalline form, but in white maffes like refined fugar, contains often a mixture of foreign metallic particles, fuch as iron, copper, and lead; but it may be purified by adding to a folution of it pure zinc, by which the above metals will be precipitated: if the folution be then filtered, and expofed to cryftallife, you will obtain pure white vitriol.

By the nitrous acid, zinc is diffolved with a ftrong effervefcence and in great quantity producing cryftals : if you pour alcohol over thefe and diftil them, you will obtain very good edulcorated fpirit of nitre. It diffolves alfo in the muriatic acid, and emits a ftrong offenfive vapour; this clear folution faturated cannot be brought to fhoot into cryftals : if you reduce it by evaporation to a gelatinous mafs, and place it in a retort over the fire, you obtain, in the fame manner as when you diffil zine with fal-ammoniac and corrofive fublimate, butter of zine of a fomewhat thick confiftence.

It is foluble alfo in aqua-regia, and by that acid gives a triple neutral falt, in the fame manner as fal-ammoniac. It diffolves likewife in concentrated acetous acid, and hoots into cryftals : the remaining acids, viz. of fparry fluor, arfenic, borax, fugar, tartar, forrel, citrons, ants, phofphorus, and fat, exercife an action over zinc alfo. The alcaline folvents do the fame; and the procefs furceeds beft with a concen- 
trated folution of the volatile, not cautic alcali, during which an effervefcence is obferved, and by which the zinc exhibits traces of an acid: the produce is cryftals of a neutral falt.

Flowers of zinc, like zinc itfelf, are foluble in an acid; but with this difference, that no effervefcence takes place. Thefe flowers are produced during the fufion of zinc in an open crucible, when the heat is increafed to above 370 degrees. The metal then inflames with a whitilh-green fame of a dazzling brightnefs, which feems to diffufe over the faces of thofe prefent a death-like palenefs; and the metal, by being deprived of its inflammable matter, (united to nxygen, is converted into a tender calx; which, by the violence of the inflammation, is, on account of its lightnefs, carried upwards like wool or a cobweb. Zinc, calcined in this manner, is called the flowers of zinc, and alfo pbilofoplic wool, not to mention other fingular appellations of the alchemifts: During this operation zinc exhibits fome phenomena, fuch as the fmell, the flame, \&c. which are fimilar to thofe that occur during the combuftion of phofphorus; and therefore people were led to fuppofe that the phofphoric acid was contained in zinc. By the above procels the weight of this calx is increafed a tenth part, and, as fome have remarked, even more, and at the fame time it becomes fixed. When expofed on coals to the blow-pipe, it becomes yellow, and on cooling refumes its whitenefs, which is a proof that the flowers of zinc are genuine. It can be fufed into a yellowifh-brown glafs, and, by adding the inflammable matter, can be reduced in clofe veffels.

In a clofe veffel, expofed to a violent heat, zinc goes over in a metallic form, and by thefe means acquires the property of creaking, when it breaks like tin. It can alfo be brought to fuch a ftate that it may be drawn out into thin plates, and be flatted between metal cylinders; fome fpecimens of which, by M. Sage of Paris, and M. Kratz of Berlin, $I$ have in my poffefion. Zinc may be combined with the 
greater part of metals, but not with lead, iron, or bifmuth; and it may be amalgamated with quickfilver. This amalgam of zinc is very proper for Atrengthening the power of an electric machine, and Higgins has given a prefcription for preparing it. In the dry way it has the greateft affinity with copper, and produces with it a more or lefs yellow compofition, which can be obtained by no other metal. In this refpect, then, it is effentially different from all other metals, and becomes itfelf a very ufeful one, as it is ufed for brafs, pinchbeck, prince's metal, bronze, Manheim gold, and in fire-works, \&c.

It is very remarkable, in regard to zinc, that neither fulphur nor liver of fulphur * produces on it any effect; whereas gold; which fulphur cannot overcome, is diffolved by liver of fulphur.

On this occafion I cannot omit making mention of the celebrated alkaheft of Refpur, who believed, that when he alcalifed zinc and rendered it caufic, and had obtained from it a purple-coloured mass, volatile in the open air, he had found out a menftruum, by which he could radically diffolve all metals. A paradoxical pofition, which was long adopted by the gold-making alchemifts, but which has never been realifed.

[To be concluded in next Number.]

VI. Defcription of an Aflay-furnace, witb an Apparatus for meafuring the Degree of Heat employed: By $M r$. David Mushet of the Clyde Iron Works. Communicated by the Autbor.

$\mathrm{I}_{\mathrm{N}}$ $\mathrm{N}$ my laft paper I mentioned, that, in order to facilitate the operations of the affay-furnace, and to compare the various degrees of heat in which different experiments are

* It has been afcertained that zinc and fulphur can be united; but the procefs is difficult, on account of the eafy oxidation and volatility of the zinc. See Men. de Dijon, $78_{3}$. 